\title{
Pengembangan Model dan Simulasi Berbasis Agen untuk Adopsi Layanan Bank Sampah di Kota Semarang
}

\author{
Halim Qista Karima ${ }^{1}$, Bertha Maya Sopha ${ }^{1}$ \\ ${ }^{1}$ Program Studi Teknik Industri, Fakultas Teknik, Universitas Gadjah Mada \\ JL. Grafika No.2, Yogyakarta, 55281 \\ Penulis untuk Korespondensi/E-mail: halim.qista.k@mail.ugm.ac.id
}

\begin{abstract}
Abstrak - Pemerintah Kota Semarang melakukan pembentukan bank sampah untuk menekan jumlah sampah di tempat pembuangan akhir. Masih bayak masyarakat di Kota Semarang yang belum mengikuti program tersebut. Pada penelitian ini dilakukan pemodelan untuk meningkatkan partisipasi masyarakat dalam mengelola sampah. Keikutsertaan masyarakat dipengaruhi oleh beberapa faktor yaitu intention, sosial norm, jarak menuju recyclingsiteagent dan outcome. Intention seseorang dalam melakukan pengelolaan sampah secara signifikan dipengaruhi oleh awareness of consequences, ascription of responsibility dan personal norm. Pemodelan dan skenario menggunakan metode agent based modeling, menghasilkan usulan kebijakan yaitu dengan mendirikan empat bank sampah. Melalui keputusan tersebut mampu menghasilkan 93\% partisipasi rumah tangga dalam mengelola sampah dan 2,4 ton sampah yang dikumpulkan hingga periode ke 60 minggu.
\end{abstract}

Abstract - Semarang government has established a Waste Bank to reduce the amount of waste in landfills. There are still many people in Semarang who have not participated in this program. This research modeling aims to increase public participation in managing waste. Public participation is influenced by intention, social norm, and distance to recycling site agents as well as the outcome. An intention to of managing waste is significantly influenced by awareness of consequences, the ascription of responsibility and personal norm. In this study using agent-based modeling. The results obtained from this model and scenarios are the intervention to establishing four Waste Bank. It produced 93\% of households participating in managing waste and 2.4 tons of garbage collected in the 60 weeks.

Keywords - Agent-based modeling, Norm Activation Model, Waste Separation Behavior, Bank Sampah, Semarang.

\section{PENDAHULUAN}

$\mathrm{S}$ ampah menjadi permasalahan di beberapa negara termasuk Indonesia. Permasalahan sampah ini dapat dijumpai di beberapa kota besar di Indonesia salah satunya di kota Semarang. Produksi sampah di kota Semarang saat ini mencapai angka 1.200 ton per hari. Hal tersebut menjadi perhatian Pemerintah kota Semarang agar jumlah sampah bisa ditekan. Pengelolaan sampah berbasis masyarakat terus dikembangkan oleh Dinas Lingkungan Hidup (DLH) kota Semarang. Salah satu yang saat ini gencar dilaksanakan adalah pembentukan bank sampah di setiap kelurahan. Hingga saat ini tercatat ada 220 bank sampah di seluruh Kota Semarang. Jumlahnya lebih banyak dari jumlah kelurahan di kota Semarang yaitu 177, meski demikian belum semua masyarakat kota Semarang mampu ikut berpartisipasi dalam kegiatan bank sampah tersebut [1].

Kota Semarang menunjuk kelurahan Tinjomoyo sebagai kelurahan percontohan peduli sampah. Terdapat tiga bank sampah yang telah didirikan sampai tahun 2019. Pendirian bank sampah sebagai bentuk kegiatan sosial kemasyarakatan, namun tidak dipungkiri bahwa kegiatan tersebut membutuhkan biaya operasional sebagai penggerak kegiatan. Kegiatan tersebut juga diharapkan mampu meningkatkan kesejahteraan / perekonomian pengurus dan anggota bank sampah. Untuk memperoleh pendapatan yang maksimal diperlukan strategi bagi masing-masing bank sampah. Pada tingkatan bank sampah dapat melakukan strategi 
penentuan harga dan layanan. Pada tingkatan investor, dapat menambah jumlah bank sampah akan mempermudah akses layanan bagi masyarakat sehingga memperbanyak jumlah partisipasi masyarakat. Namun banyaknya bank sampah juga dapat menimbulkan persaingan antar bank sampah dan mempengaruhi pendapatan antar bank sampah.

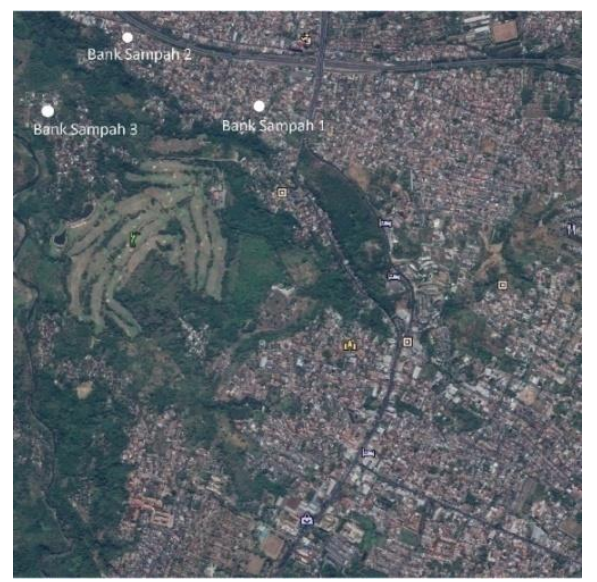

Gambar 1. Lokasi Bank Sampah 1, 2 \& 3 di Kelurahan Tinjomoyo

Berdasarkan uraian diatas makan dapat dirumuskan masalah dalam penelitian ini yaitu faktor apa saja yang mempengaruhi perkembangan jumlah partisipasi masyarakat dan kebijakan apa yang efektif untuk meningkatkan pendapatan masing masing bank sampah, persentase partisipasi masyarakat, dan jumlah sampah yang dapat ditekan. Tujuan dari penelitian ini adalah membangun model simulasi untuk adopsi layanan bank sampah. Mengevaluasi intervensi dan memberi rekomendasi untuk meningkatkan partisipasi masyarakat, pendapatan bank sampah dan jumlah sampah yang dapat ditekan.

Perkembangan model yang menjelaskan tentang behavior seseorang dalam melakukan pengelolaan sampah telah berkembang dari segi penentuan variable keputusan behaviordan metode model estimasi yang digunakan. Beberapa peneliti telah mengkaji variabel penentu keputusan behavior seseorang untuk melakukan pengelolaan sampah yaitu dengan menggunakan Theory Planed Behavior (TPB), Norm Activation Model (NAM) serta kondisi demografis seseorang. Metode estimasi yang digunakan untuk memodelkan variable tersebut diantaranya Regresi, Structural Equation Modeling (SEM) dan Agent Based Modeling (ABM).
Menurut [2] menguji metode TPB, NAM dan facilities accessibility untuk menentukan behavior seseorang dalam mengelola sampah. Theory of Planned Behavior (TPB) menyatakan bahwa selain sikap dan norma subjektif, seseorang juga mempertimbangkan kontrol perilaku [4]. Metode NAM digunakan karena metode tersebut merupakan metode yang menjelaskan tentang kesatuan antara kesadaran, tanggung jawab, dan norma personal yang mempengaruhi intensi dan perilaku individu dalam pro lingkungan [3]. Dari penelitian tersebut dinyatakan bahwa behavior signifikan dipengaruhi oleh fasilitas dan stimulus pemerintah dalam menunjang kemudahan melakukan kegiatan tersebut. Kontrol perilaku dalam TPB tidak signifikan mempengaruhi intention behavior seseorang.Sedangkan personal norm dan social norm mempengaruhi terhadap intention behavior secara signifikan.

Pada penelitian behavior pro lingkungan tidak ada jaminan bahwa seseorang dengan intention tinggi maka akan melakukan behavior sesuai dengan intention [5]. Sehingga untuk memodelkan behavior beberapa peneliti menambahkan faktor lain yang mempengaruhi behavior seseorang. Pada penelitian [6] menegaskan bahwa sosial norms mempengaruhi secara langsung terhadap behavior. Selain itu jarak tempuh menuju recycling agent juga menjadi faktor yang mempengaruhi secara langsung. Menurut [7] menjelaskan bahwa jarak penampungan sampah mempengaruhi seseorang untuk membuang sampah, semakin dekat jarak tempat pengolahan sampah maka akan semakin tinggi kemungkinan seseorang melakukan perilaku pengolahan sampah. Selain itu, outcome (keuntungan finansial) dari penjualan sampah merupakan faktor yang signifikan mempengaruhi behavior seseorang dalam partisipasi kegiatan bank sampah [5].

Menurut [8] telah memodelkan dengan multi agent based simulation didasarkan metode TPB dengan faktor keputusan masing-masing jenis agent yang berbeda. Menurut [9] bahwa ABM adalah suatu metode untuk mempelajari suatu sistem yang terdiri dari agent yang saling berinteraksi dan memunculkan sifat baru karena interaksi dan mampu merepresentasikan individu atau agent dalam sebuah sistem sosial yang dinamis. Sifat baru yang muncul tersebut tidak bisa disimpulkan secara sederhana dengan menyatukan semua sifat yang dimiliki oleh agent. Menurut [10] telah memodelkan dan mensimulasikan kesediaan seseorang dalam melakukan pengelolaan sampah. 
Model simulasi yang telah dibangun yaitu model dengan multi agent based modeling yaitu memiliki lebih dari satu jenis agent yang dimodelkan yaitu resident agent, environmental sanitation agent dan recycling site agent. Residentagent memiliki tiga behavioryaitu tidak mengumpulkan sampah, mengumpulkan sampah dan menjual sampah. Didasarkan dengan Theory Planed Behavior, ketiga behaviorresident agent dipengaruhi oleh cost, profit, time cost dan awareness.

\section{METODE PENELITIAN}

Subjek penelitian adalah orang-orang yang memiliki kewenangan dalam keluarga dalam mengelola sampah serta keuangan keluarga dan masyarakat yang berdomisili di Kota Semarang. Adapun yang menjadi objek penelitian adalah layanan bank sampah yang berada di Kelurahan Tinjomoyo dan sekitarnya.

Penelitian ini memiliki beberapa tahapan utama pengerjaan. Berikut tahapan-tahapan yang dilakukan agar tujuan pemodelan tercapai:

\section{Model Konseptual}

Model konseptual pengambilan keputusan adopsi layanan bank sampah yang bersifat teoritis. Adapun model konseptual yang digunakan pada penelitian ini adalah model konseptual yang didasari penelitian sebelumnya, data empiris dan observasi. Model konseptual selanjutnya disusun pada ODD protocol. ODD atau Overview, Design Concepts, andDetail merupakan cara mendesain model, serta menggambarkan elemen dari konsep desain yang dibangun dalam Agent Based Modeling.

\section{Implementasi Model di Net Logo}

Pada tahap ini dilakukan proses coding dari spesifikasi model yang telah dibangun ke dalam perangkat lunak Net Logo.

\section{Verifikasi dan Validasi Model}

Verifikasi dilakukan untuk melihat kesesuaian implementasi model di Net Logo dengan rancangan model. Adapun tes verifikasi yang dilakukan adalah structural debuggingdan uji kasus sederhana. Kemudian dilakukan validasi model, untuk menguji kepercayaan tingkat representation model terhadap sistem nyata. Pengujian model validasi dengan menggunakan extreme condition test dan dibandingkan dengan teori terdahulu.
Model Skenario

Pada tahapan ini dilakukan uji coba dan analisa skenario mengenai pemilihan jenis intervensi yang dapat dilakukan agar jumlah partisipasi meningkat. Keluaran tahapan ini adalah intervensi yang efektif digunakan untuk memicu perkembangan nasabah bank sampah.

\section{HASIL PEMBAHASAN}

Pemodelan adopsi layanan bank sampah melibatkan beberapa stakeholder diantaranya agent household, bank sampah dan pengepul keliling. Setiap agent memiliki behavior masing-masing, dapat dilihat pada Gambar 2,

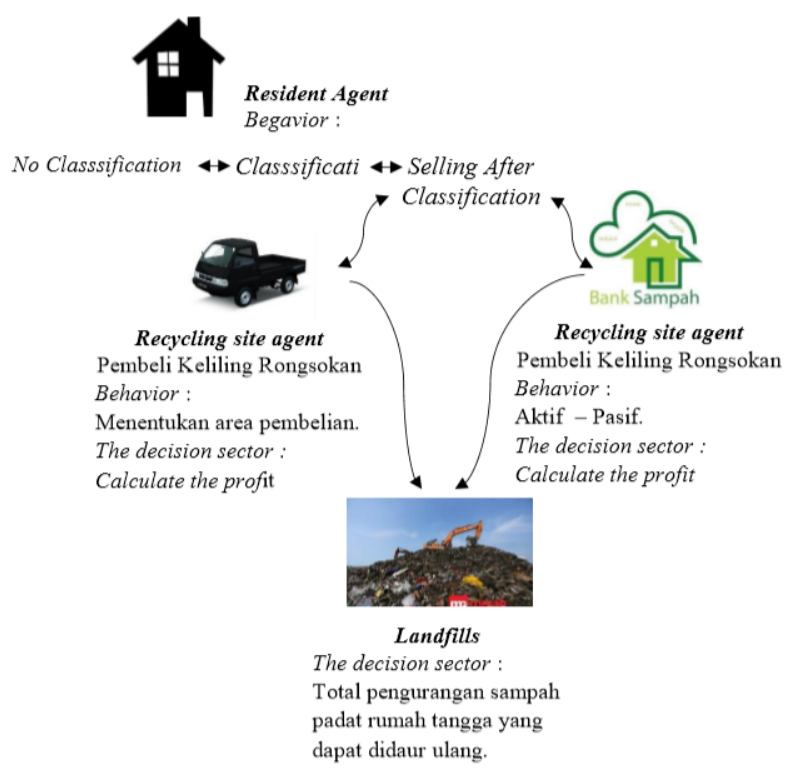

Gambar 2. Model konseptual adopsi layanan Bank Sampah

\section{Model Spesifikasi}

Model Estimasi Nilai Intention

Norm Activation Model (NAM) terdiri dari variabel dependent yaitu intention (IT) dan variabel independent yaitu awareness of consequence (AC), personal norm $(P N)$ dan ascription of responsibility (AR).

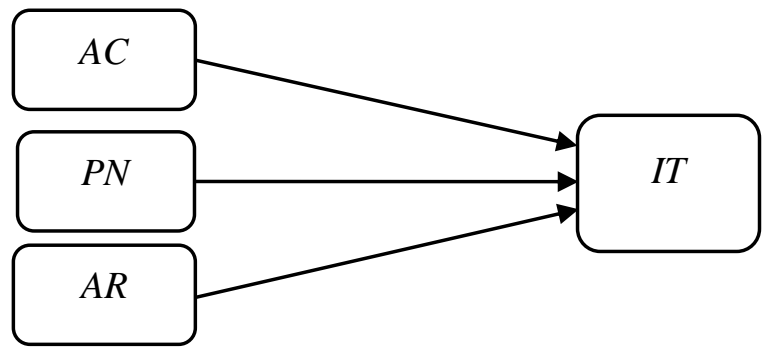

Gambar 3. Model konseptual Norm Activation Model 
Berdasarkan pengujian anova diketahui nilai signifikansi pengaruh variabel independent terhadap dependentvariable secara bersama sama adalah 0,000 lebih kecil dari 0,05. Sehingga dapat disimpulkan bahwa terdapat pengaruh Personal Norm, Awareness of Consequences dan Ascription of Responsibility terhadap Intention. Dari pengujian tersebut, maka diperoleh persamaan regresi linear berganda sebagai berikut:

$\mathrm{IT}=-6,602+0,608 \mathrm{AC}+0,406 \mathrm{AR}+0,414 \mathrm{PN}(1)$

Keterangan:

IT : Intention(3-15)

AC : Nilai Awareness of Consequences (3-15)

AR : Nilai Ascription of Responsibility(3-15)

PN : Nilai Personal Norm(3-15)

\section{Model Penentuan Keputusan Alternatif}

Untuk menentukan alternatif bank sampah terbaik, agenthousehold mempertimbangkan beberapa variabel keputusan diantaranya outcome [5], jarak menuju recycling site agentdan pengaruh neighbor [7]. Untuk mengetahui bobot dari masing-masing variabel maka dilakukan pengumpulan data matriks pairwise comparison antar variabel dan perhitunganbobot variabel dengan menggunakan metode Analytic Hierarchy Process (AHP)

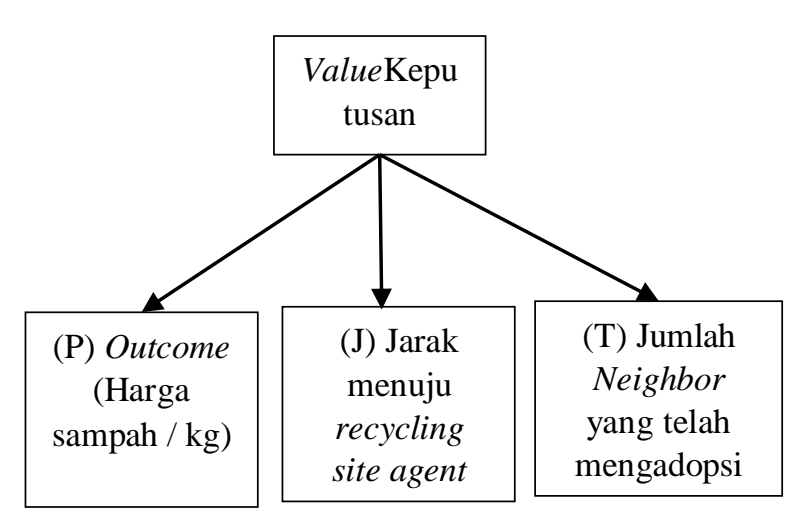

Decision alternative:

- Pengepul Keliling

- Bank Sampah 1, 2, 3, 4, dan 5.

Gambar 4. Kerangka keputusan pemilihan Bank Sampah
Masing-masing responden mengisi matriks pairwise comparison, sehingga memiliki bobot variabel yang berbeda antara responden (agent) satu dengan yang lain. Berikut perhitungan bobot variabel keputusan:

Tabel 1. Matriks Pairwise Comparison

\begin{tabular}{|c|c|c|c|c|c|c|c|}
\hline & $\mathbf{T}$ & $\mathbf{J}$ & $\overline{\mathbf{P}}$ & \multicolumn{3}{|c|}{ Normalisasi } & Bobot \\
\hline$\overline{\mathbf{T}}$ & 1 & $1 / 7$ & $1 / 3$ & 0,09 & 0,10 & 0,08 & 0,09 \\
\hline $\mathbf{J}$ & 7 & 1 & 3 & 0,64 & 0,68 & 0,69 & 0,67 \\
\hline $\mathbf{P}$ & 3 & $1 / 3$ & 1 & 0,27 & 0,23 & 0,23 & 0,24 \\
\hline & 11 & 1,48 & 4,33 & 1 & 1 & 1 & 1 \\
\hline
\end{tabular}

Untuk mengetahui responden mengisi dengan benar dan konsisten maka dilakukan pengujian konsistensi sebagai berikut:

$$
\begin{aligned}
C I & =\frac{\lambda-n}{n-1} \\
& =\frac{3,007-3}{3-1} \\
& =0,004 \\
\mathrm{CR} & =\mathrm{CI} / 0,58 \\
\mathrm{CR} & =0,006
\end{aligned}
$$

Berdasarkan hasil perhitungan nilai konsistensi, nilai konsistensi CR yaitu 0,006 kurang dari 0,1 atau $\mathrm{CR}<0,1$ maka hasil perhitungan tersebut dinyatakan konsisten. Perhitungan tersebut diulang untuk setiap responden. Dari 103 responden hanya 73 responden bobot dinyatakan konsisten.

\section{Model Prediksi Behavior Classification dan No Classification}

Menentukan persamaan probabilitas agenthousehold dalam menentukan behavior mengumpulkan sampah/classification. Nilai probabilitas diperoleh dari persamaan regresi linear logistic.

Setelah dilakukan pengujian goodness of fit dinyatakan bahwa model yang dibangun mampu memprediksi behavior dengan baik. Maka diperoleh persamaan untuk menentukan probabilitas, sebagai berikut:

$$
\pi(1)=\frac{\exp (-6,04+0,433 I T-0,12 J+3,11 N+0,002 P)}{1+\exp (-6,04+0,433 I T-0,12 J+3,11 N+0,002 P)}
$$




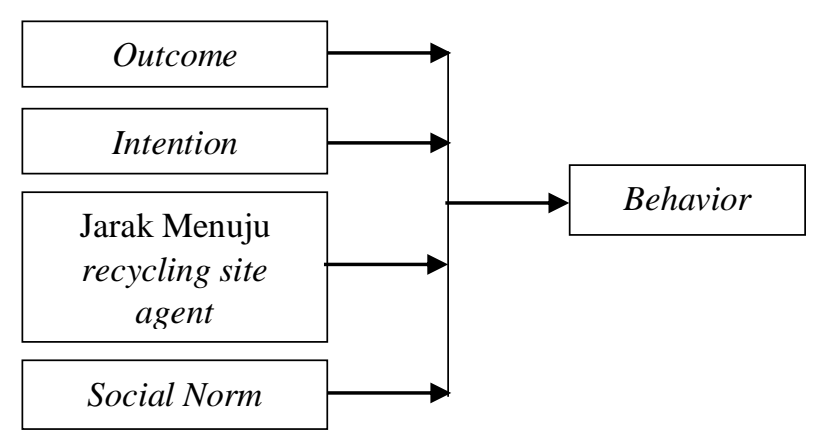

Gambar 5. Model keputusan dengan Regresi Linear Logistik Biner

\section{Model Konseptual ODD}

\section{Purpose}

Purpose dari model ini adalah memodelkan sistem adopsi layanan bank sampah oleh masyarakat berdasarkan behavior seseorang, guna mengevaluasi menentukan intervensi sebagai upaya peningkatan pendapatan bank sampah, persentase partisipasi masyarakat, dan jumlah sampah yang dapat ditekan.

\section{Entities state variables dan scale}

\section{Entities:}

Agent Household:

AC : Nilai Awareness of Consequences

AR : Nilai Ascription of Responsibility

PN : Nilai Personal Norm

Bs : behavior "NC"(no classification), " $\mathrm{C}$ " (classification) dan "SAC" (selling after classification).

t :lama waktu seseorang untuk mengumpulkan sampah hingga dijual

$\mathrm{K} \quad$ : nilai tertinggi dari alternative keputusan

D : bank sampah yang dipilih ditunjukkan sebagai nomor bank sampah "0 1234 5"

Y : status agent household menjual (SAC) pada (nomor bank sampah) "SAC0 SAC1 SAC2 SAC3 SAC4 SAC5 SAC6 t"

$\mathrm{BP}$ : bobot pengaruh harga

BJ : bobot pengaruh jarak

BN : bobot pengaruh lingkungan / tetangga

Agent Bank Sampah:

Rv : Pendapatan masing-masing bank sampah per periode waktu (Rv1, Rv2, Rv3, Rv4, Rv5)

$\mathrm{p} \quad$ : Harga sampah per kilogram $(\mathrm{p} 1, \mathrm{p} 2, \mathrm{p} 3$, p4, p5) x dan y : Koordinat Lokasi

AT : Status kepemilikan alat transportasi

Agent Pengepul Keliling:

p : Harga sampah per kilogram (p6)

Rv : pendapatan pengepul sampah per periode

Koordinat Lokasi: Random

Scale:

Waktu : 1 tick = 2 minggu

Luas : 1 patch $=27$ meter

Process Overview dan Scheduling Process Overview

Simulasi dilakukan dari proses inisialisasi kondisi awal. Agenthousehold: memiliki 3 behavior yaitu, tidak mengklasifikasikan sampah (NC), mengklasifikasi sampah (C) dan menjual sampah setelah klasifikasi (SAC). Dari behavior tidak mengklasifikasikan sampah ke mengklasifikasikan sampah ditentukan oleh nilai probabilitas yang diperoleh dari fungsi persamaan regresi linear logistic. Dari mengklasifikasikan sampah menuju mengumpulkan sampah, ditentukan berdasarkan threshold waktu yang ditentukan. Agent Bank Sampah memiliki 2 (dua) behavior yaitu aktif dan pasif. Aktif berarti melayani penjemputan pada batas area tertentu, sedangkan pasif yaitu tidak melayani penjemputan sampah. Agent pengepul sampah keliling memiliki behavior berpindah secara random ke setiap household

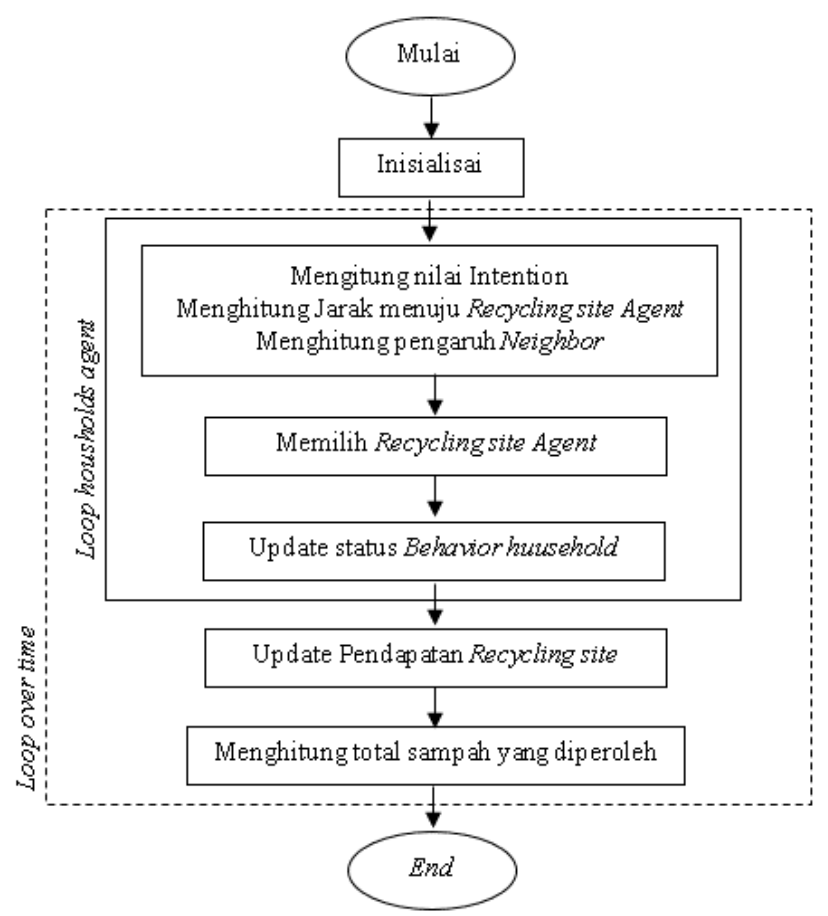

Gambar 6. Flow chart proses simulasi model 


\section{Design Concept}

Bagian ini menjelaskan bagaimana model mengimplementasikan serangkaian konsep dasar yang penting untuk merancang model ABM. Berikut merupakan penjelasan bagian-bagian dari design concept:

Basic principles pada model ini yaitu keputusan seseorang agent household dalam adopsi layanan bank sampah. Keputusan agent household dipengaruhi oleh beberapa hal yaitu intention, sosial norm, outcome, dan jarak menuju bank sampah. Agent household akan memilih bank sampah yang paling menguntungkan baginya dengan membandingkan jarak, price dan pengaruh sosial.

Emergence dalam model ini yaitu pendapatan yang dihasilkan oleh masing-masing agent bank sampah dan pengepul keliling, persentase agent house hold yang berpartisipasi dalam layanan bank sampah dan jumlah sampah yang mampu dikumpulkan. Selain dari hasil numerik, juga menghasilkan pola persebaran behavior agent household yang terjadi akibat masing-masing keputusan behavior house hold. Agent household memiliki perilaku adaptif dengan behavior antara lain no classification, classification dan selling after classification. Agent household juga akan memutuskan bank sampah yang menjadi alternative terbaik baginya. Keputusan bank sampah dipilih dari beberapa alternative agent bank sampah berdasarkan variabel keputusan yang telah ditentukan. Interaksi yang ada dalam model yaitu interaksi antara agent bank sampah dan agent household, agent household dan agent household yang lain. Interaksi agent household dan bank sampah yaitu jika suatu bank sampah memiliki alat transportasi maka akan mengubah jarak agent household ke bank sampah tersebut menjadi nol, hal ini didasari oleh sistem penjemputan yang dilakukan bank sampah. Interaksi antara agent household yaitu jumlah adopter pada agent household di sekitarnya akan mengubah jumlah value dari pengaruh social norm.

Terdapat beberapa proses stokastik untuk memodelkan beberapa kondisi yang sulit dimodelkan pada model ini. Proses stokastik digunakan pada penentuan jumlah sampah yang ditabung/dijual, dilakukan pendekatan random dengan distribusi normal. Selain itu, lama waktu (threshold) agent rumah tangga dalam mengumpulkan sampah, dilakukan random dengan distribusi normal. Output dari model yang digunakan untuk dilakukan pengamatan yaitu berupa grafik data. Grafik kumulatif pendapatan setiap bank sampah, grafik persentase agent household yang melakukan klasifikasi sampah dan menjualnya, serta total sampah yang dapat dikumpulkan dan dikelola. Kondisi awal yang dimodelkan pada agenthousehold yaitu koordinat lokasi, value dari awareness of consequences, ascription of responsibility, personal norm, bobot pengaruh jarak, outcome, dan social norm serta behavior awal agent household.

\section{Input Data}

Input pada model ini yaitu jumlah bank sampah, koordinat awal bank sampah, harga sampah pada bank tersebut dan status kepemilikan transportasi.

\section{$\underline{\text { Sub model }}$}

Sub model menjelaskan spesifikasi model untuk estimasi nilai intention seseorang dalam adopsi layanan bank sampah. Menentukan keputusan behavior adopsi layanan bank sampah ditentukan oleh nilai probabilitas yang diperoleh dari persamaan linear logistic. Sedangkan untuk menentukan alternative bank sampah yang dipilih berdasarkan perkalian value dan bobot pengaruh variabel masing-masing agent household.

\section{Verifikasi dan Validasi Model}

Verifikasi dilakukan untuk melihat kesesuaian implementasi model di Net Logo dengan rancangan model konseptual. Adapun tes verifikasi yang dilakukan adalah menguji model dengan kasus sederhana. Kasus sederhana terdiri dari 8 agent household dan 2 agent bank sampah. Hal ini juga memastikan syntax yang ditulis tidak ada permasalahan debugging.

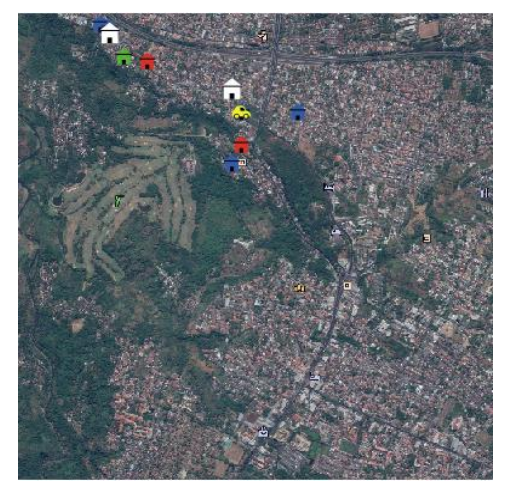

Gambar 7. Hasil simulasi pada uji verifikasi

Pada Gambar 8 dapat dilihat output pendapatan yaitu adanya kenaikan pendapatan pada bank 
sampah 2, Jika dilihat pada Gambar 7 terdapat rumah berwarna hijau yang berarti sedang menabung sampah, sehingga behavior tersebut dianggap telah sesuai yang diinginkan. Terdapat penurunan jumlah partisipasi masyarakat, bahwa terdapat 2 agent household yang tidak mengumpulkan sampah. Dari beberapa uraian tersebut, disimpulkan bahwa pergantian behavior model telah berhasil digambarkan dengan baik dan menghasilkan output yang diharapkan.

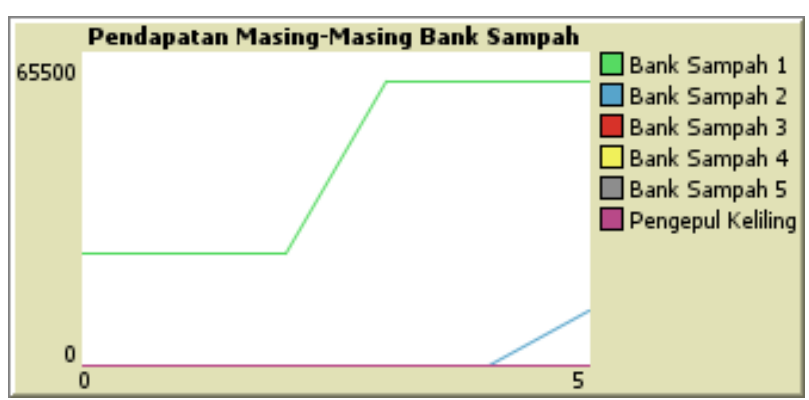

Gambar 8. Output pendapatan bank sampah pada uji validasi

Tahap validasi model digunakan untuk membangun kepercayaan tingkat representation model terhadap sistem nyata. Pengujian yang dilakukan menggunakan extreme condition test dan dibandingkan dengan teori yang sudah ada atau penelitian terdahulu.

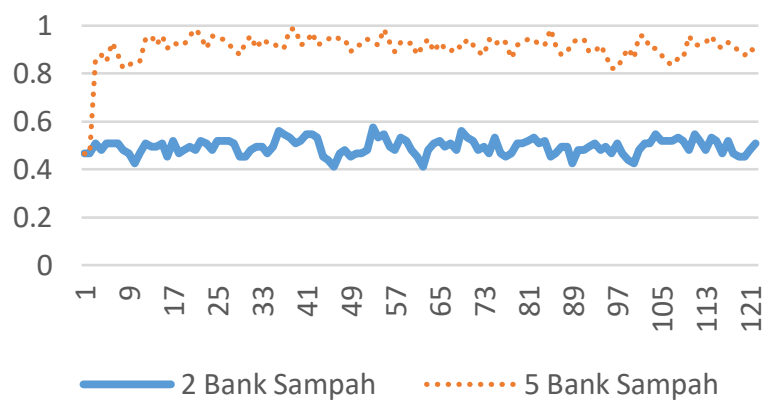

Gambar 9. Persentase partisipasi agent household pada uji extreme condition jumlah bank sampah

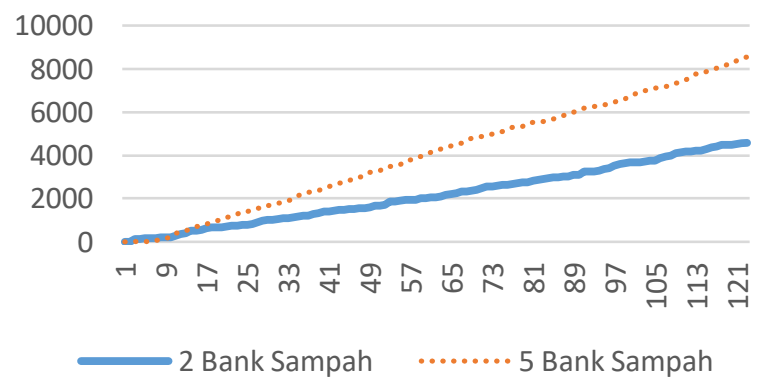

Gambar 10. Jumlah sampah yang terkumpul pada uji extreme condition jumlah bank sampah
Dari uji extreme condition pada jumlah bank sampah menunjukan hasil yang berbeda antara pengujian 2 dan 5 bank sampah. Dengan 5 bank sampah persentase partisipasi agent household dan jumlah sampah yang dikelola lebih besar dari pada pengujian dengan 2 bank sampah. Sehingga banyaknya bank sampah dan jarak menuju bank sampah akan mempengaruhi tingkat adopsi layanan bank sampah oleh agent household. Hal tersebut juga dikemukakan oleh [6]. Akses kemudahan mendapatkan layanan pengelolaan bank sampah juga dapat mempengaruhi behavior seseorang dalam melakukan pengelolaan sampah [2].

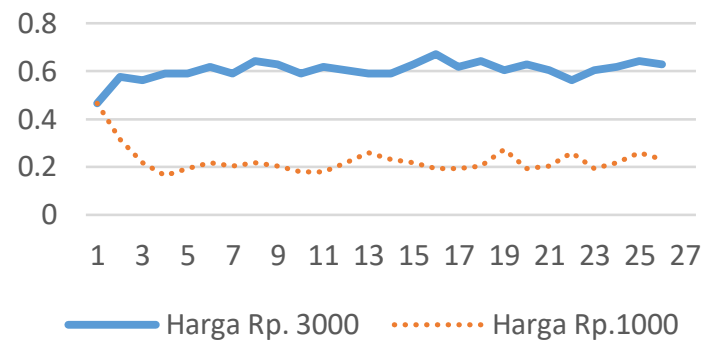

Gambar 11.Persentase agent household pada uji extreme condition perubahan harga

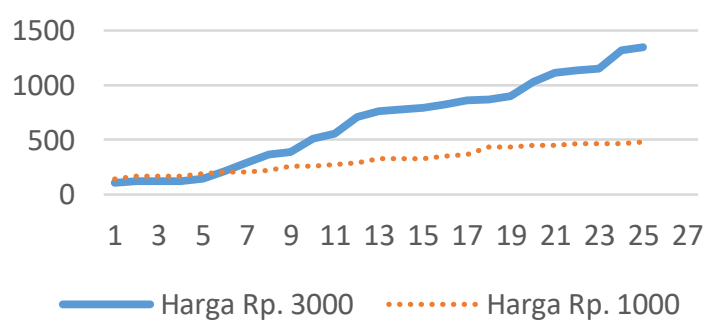

Gambar 12.Jumlah sampah yang terkumpul pada uji extreme condition perubahan harga

Uji extreme condition juga dilakukan pada outcome yang dihasilkan dari pengelolaan sampah. Outcome bagi agent household yaitu besaran harga sampah per Kg. Diperoleh hasil bahwa terdapat perbedaan antara harga $\mathrm{Rp} 3.000$ dan Rp 1.000. Dengan harga Rp3.000 persentase partisipasi agent householddan jumlah sampah lebih tinggi dari pada harga Rp1.000. Dengan demikian bahwa outcome berpengaruh pada tingkat adopsi layanan bank sampah. Menurut [5] dan [11] menjelaskan bahwa outcome bagi agent household mempengaruhi keputusan seseorang untuk mengelola sampah.

\section{Skenario Model}

Model simulasi skenario dilakukan untuk mengetahui jenis intervensi yang dapat dilakukan agar nilai tujuan performance indeks meningkat. Beberapa data input akan diuji coba untuk mencari 
intervensi yang lebih baik yaitu dengan 4 skenario pengujian. Pada skenario 1 dilakukan evaluasi terhadap kondisi yang saat ini terjadi tanpa adanya perubahan pada inisialisasi kondisi. Skenario 2 mengubah jumlah bank sampah menjadi 2 unit, dengan koordinat seperti pada Gambar 14. Skenario 3 yaitu mengubahinisialisasi kondisi banksampah menjadi 3 dengan koordinat pada Gambar 15. Skenario 4 yaitu mengubah denganmenambah banksampah menjadi 4 dengan koordinat pada Gambar 16. Koordinat bank sampah ditunjukkan pada icon rumah dengan warna putih. Sedangkan rumah dengan warna merah merupakan agent household dengan behavior no classification, warna biru yaitu classification dan warna hijau selling after classification.

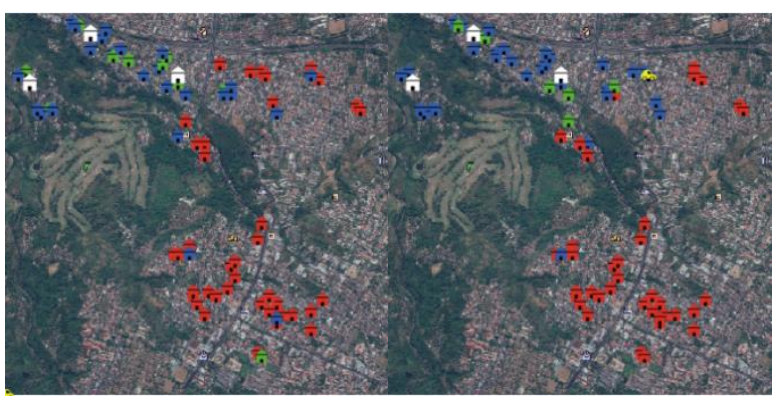

(a) Inisialisasi

(b) Hasil Simulasi

Gambar 13. Skenario 1

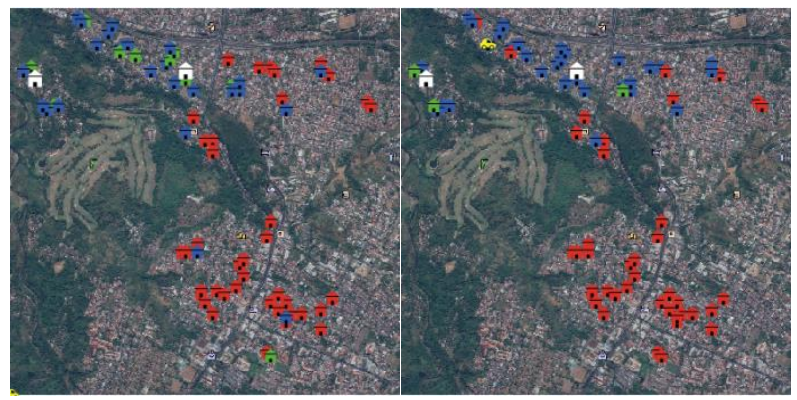

(a) Inisialisasi

(b) Hasil Simulasi

Gambar14. Skenario 2

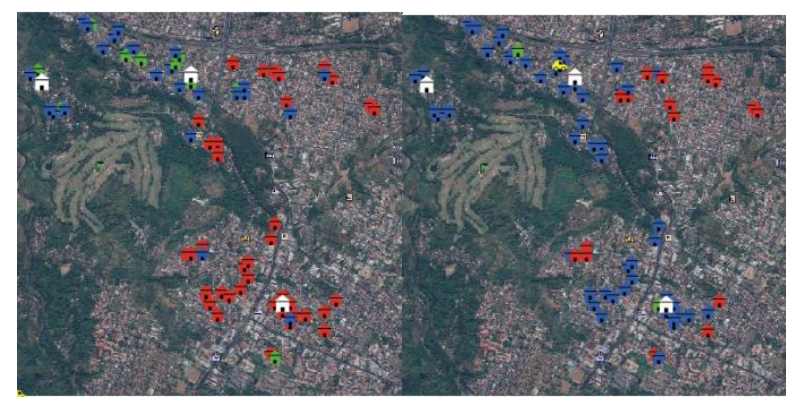

(a) Inisialisasi

(b) Hasil Simulasi

Gambar 15. Skenario 3

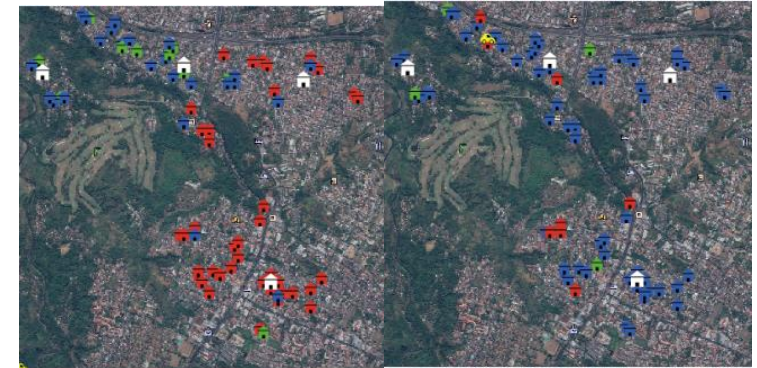

$\begin{array}{ll}\text { (a) Inisialisasi } & \text { (b) Hasil Simulasi }\end{array}$

Gambar16. Skenario 4

Perbandingan hasil skenario dilakukan untuk menentukan intervensi yang lebih baik dari beberapa skenario yang telah diujikan. Terdapat 4 skenario simulasi model. Perbandingan skenario model ditunjukkan dengan persentase partisipasi agent household yang melakukan pengelolaan sampah dan jumlah sampah yang dapat dikumpulkan. Perbandingan ditunjukkan pada Gambar 17. dan Gambar 18.

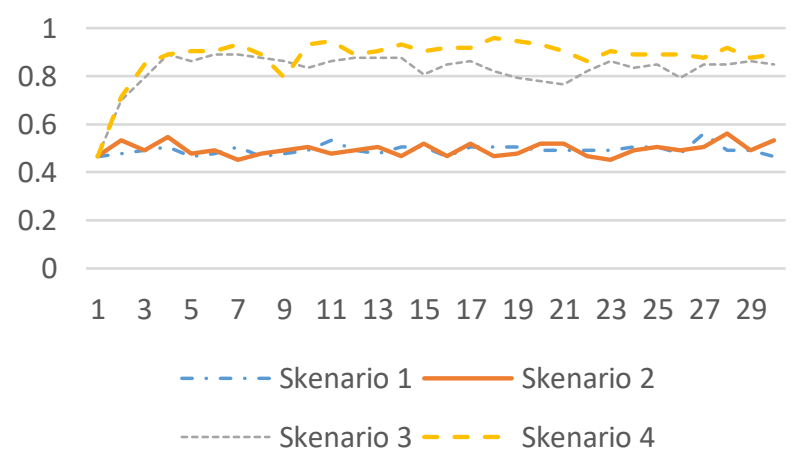

Gambar 17. Perbandingan persentase partisipasiagent household yang mengelola sampah

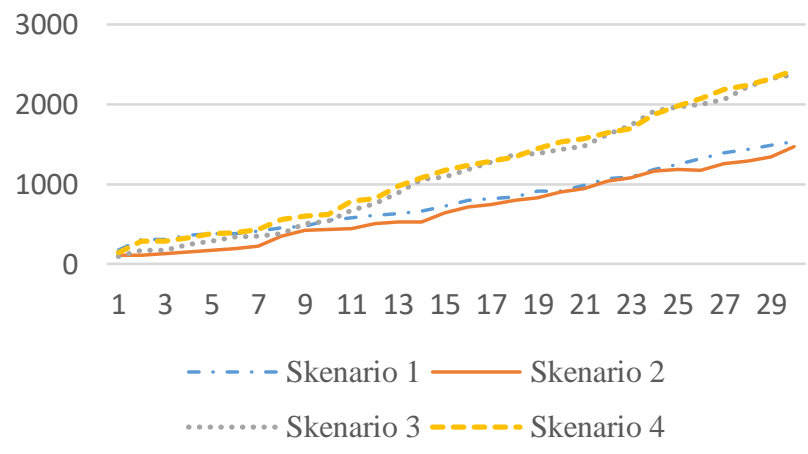

Gambar 18. Perbandingan hasil jumlah sampah yang dapat dikumpulkan

Berdasarkan hasil perbandingan diatas maka scenario 4 merupakan scenario terbaik dari beberapa scenario yang lain. Skenario 4 yaitu 
dengan menambah jumlah bank sampah pada koordinat tertentu.

Tabel 2. Hasil perbandingan dengan skenario 4

\begin{tabular}{ccccc}
\hline $\begin{array}{c}\text { Bank } \\
\text { Sampah }\end{array}$ & $\begin{array}{c}\text { Koor. } \\
\mathrm{x}\end{array}$ & $\begin{array}{c}\text { Koor. } \\
\mathrm{y}\end{array}$ & Price & $\begin{array}{c}\text { Alat } \\
\text { transportasi }\end{array}$ \\
\hline 1 & 45 & 84 & 1700 & 1 \\
2 & 6 & 82 & 1700 & 0 \\
3 & 69 & 24 & 1700 & 0 \\
4 & 78 & 80 & 1600 & 0 \\
\hline
\end{tabular}

Dari hasil simulasi diperoleh pola persebaran agent yang telah berpartisipasi mengelola sampah pada Gambar 16. Agent household didominasi oleh agent dengan keputusan alternative bank sampah 1 dan 3, dapat dilihat pada grafik Gambar 19. Bank sampah $1 \& 3$ merupakan bank sampah dengan pendapatan tertinggi.

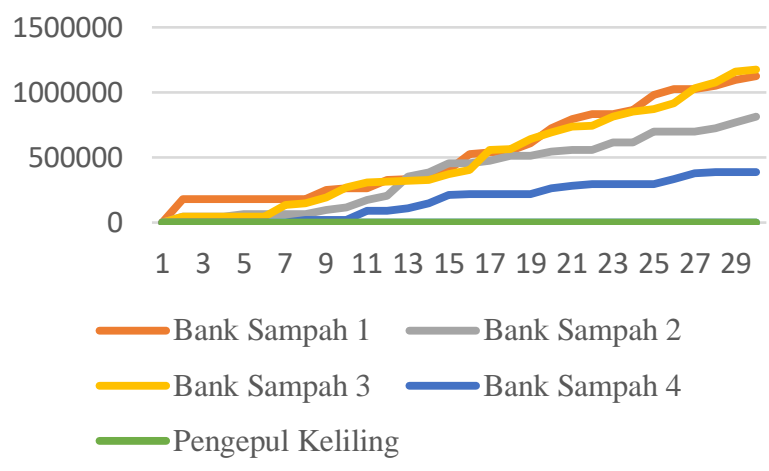

Gambar 19. Pendapatan pada masing - masing bank sampah pada skenario 4

\section{KESIMPULAN}

Penelitian ini bertujuan mengembangkan model berbasis agent pada adopsi layanan bank sampah di Kota Semarang. Model didasarkan pada perilaku masyarakat yang berbeda-beda. Perilaku seseorang dalam mengelola sampah dipengaruhi oleh intention, sosial norm, jarak menuju recyclingsiteagent dan outcome. Melalui metode Norm Activation Model, intention seseorang dalam melakukan pengelolaan sampah secara signifikan dipengaruhi oleh awareness of consequences, ascription of responsibility dan personal norm. Sedangkan keputusan seseorang dalam menentukan alternative bank sampah dipengaruhi oleh sosial norm, jarak menuju recyclingsiteagent dan outcome masing-masing recyclilng site agent.

Intervensi dan evaluasi bank sampah pada Kelurahan Tinjomoyo dan sekitarnya, diperoleh hasil dengan membangun 4 bank sampah dengan rincian 2 unit di kelurahan Tinjomoyo, 1 di kelurahan Sumurboto dan 1 di kelurahan Ngesrep. Dengan keputusan tersebut mampu menghasilkan persentase partisipasi rumah tangga yang turut serta mengelola sampah sebesar 93\% dan 2,4 ton sampah yang dikumpulkan hingga periode ke 60 minggu.

\section{REFERENSI}

[1]. E. Y. Fajlin, "Produksi sampah kota semarang 1.200 ton per hari, 46 hektar TPA Jatibarang bakal penuh", Tribunjateng.com, 2019. (online accessed 18 November 2019)

[2]. B. Zhang, K. Lai, B. Wang, Z. Wang, "From intention to action: How do personal attitudes, facilities accessibility, and government stimulus matter for household waste sorting?", Journal of Environmental Management, vol. 233, pp. 447-458, 2019.

[3]. R. Wall, D. P. Wright, A. G. Mill, "Comparing and combining theories to explain proenvironmental intentions", environment and behavior, vol. 39(6), pp. 731-753, 2007.

[4]. I. Ajzen, "Perceived behavioral control, self-efficacy, locus of control, and the theory of planned behavior", Journal of Applied Social Psychology, vol. 32, pp. 665-683,2002.

[5]. R. D. Astuti, U. Linarti, “Analisis pengaruh faktor dalam TPB dan outcome terhadap niat warga bergabung di bank sampah (Studi kasus di kota Yogyakarta)", Seminar Nasional Teknologi Terapan 2018 (SNTT), Yogyakarta,2018.

[6]. M. F. Sorkun, "How do social norms influence recycling behavior in collectivistic society? A case study from Turkey", Waste Management, vol. 80, pp. $359-370,2018$.

[7]. J. Sotamenou, S. D. Jaeger, S. Rousseau, "Drivers of legal and illegal solid waste disposal in the Global South - The case of households in Yaoundé (Cameroon)", Journal of Environmental Management, vol. 240, pp. 321-330, 2019.

[8]. M. Luo, X. Song, S. Hu, Chen, D., "Towards the sustainable development of waste household appliance recovery systems in china : an agent-based modeling 
approach", Journal of cleaner production, vol. 220, pp. 431-444, 2019.

[9]. R. Axelrod, L.Testation, "A Guide For Newcomers to Agent Based Modeling in The Social Sciences, Kenneth L. Judd and Leigh Testation (eds.)", Handbook of Computational Economics, vol. 2, 2006.
[10]. X.Meng, Z. Wen, Y. Qian, "Multi-agent based simulation for household solid waste recyclingbehavior", Resource, conservation and recycling, vol. 128, pp. 535-545, 2018.

[11]. L. Xu, M. Ling, Y. Wu, "Economic incentive and social influence to overcome household waste separation dilemma: A field intervention study", Waste Management, vol. 77, pp. 522-531, 2018. 